\title{
Compliance with diabetes guidelines at a regional hospital in KwaZulu-Natal, South Africa
}

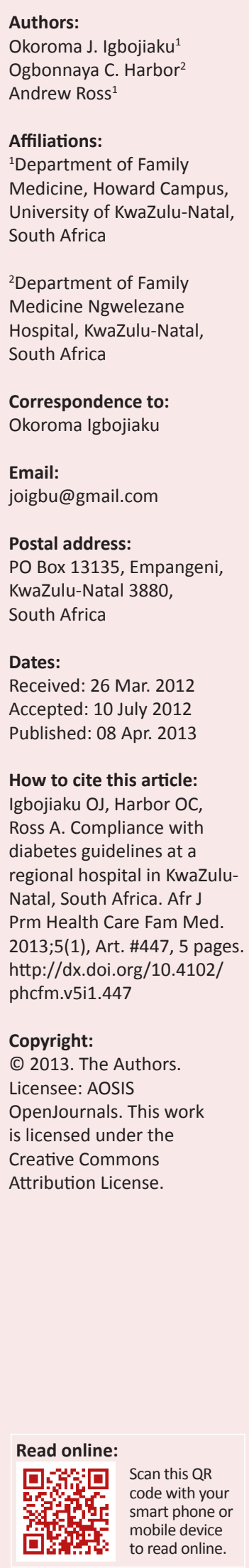

Background: Diabetes is a major problem in South Africa and throughout the world. The management of type 2 diabetes aims at maintaining normoglycaemia and preventing the development of complications arising from diabetes. The Society for Endocrine Metabolism and Diabetes of South Africa (SEMDSA) guidelines are based on a number of international trials which showed that strict control of blood sugar leads to a reduction in the development of diabetic complications. However, many studies have shown poor adherence to national guidelines by doctors caring for diabetes patients.

Objectives: The aim of this study was to assess doctors' compliance with the SEMDSA diabetes guidelines at a regional hospital in KwaZulu-Natal.

Method: Seven hundred and fifty diabetic patient records were selected by systematic sampling of cases from the diabetic clinic and reviewed against SEMDSA guidelines.

Results: Eighty three per cent of the patients had high values of glycated haemoglobin $\left(\mathrm{HbA}_{1 \mathrm{c}}\right)$. Lipid examination was rarely performed, and comprehensive foot examination was carried out in only $6 \%$ of patients. Although blood pressure and weight were regularly checked, these examinations were performed by the nursing staff, and medical staff generally did not respond to abnormal results.

Conclusion: This study demonstrates poor compliance with current diabetic guidelines. There is an urgent need to review how guidelines are disseminated and implemented in South African public sector hospitals if evidence-based guidelines are to have any impact on patient care.

La conformité avec les indications nationales à une clinique de diabète d'un hôpital régional dans KwaZulu-Natal ; Afrique du Sud

Fond: Le diabète est un problème majeur à Afrique du Sud et à travers le monde. La direction de type 2 objectifs de diabète à maintenir de normoglycaemia et empêcher le développement de complications résultant du diabète. La Société pour le Métabolisme et Diabète Endocrine d'Afrique du Sud (SEMDSA) les indications sont fondées sur un nombre de procès internationaux qui ont montré ce contrôle strict de glucide mene à une réduction dans le développement de complications diabétiques. Cependant beaucoup d'études ont montré l'adhésion pauvre aux indications nationales par les médecins qui soignent les malades de diabète.

Objectifs: L'objectif de cette étude était d'évaluer de la conformité des médecins avec les indications de diabète de SEMDSA à un hôpital régional dans Kwa Natal zoulou.

Méthode: Sept cent et cinquante dossiers patient diabétiques ont été choisis par l'échantillonnage systématique de cas de la clinique diabétique et ont été réexaminés contre les indications de SEMDSA.

Résultats: Quatre-vingt trois pourcent des malades a eu haut des valeurs de glycated haemoglobin (HbA1c). L'examen de lipide a été rarement fait, l'examen de pied complet a été seulement fait pour six pourcent de malades. Bien que la tension artérielle et le poids ont été régulièrement vérifiés, ces examens ont été faits par le personnel qui soigne et le personnel médical n'a pas répondu généralement aux résultats anormaux.

Conclusion: Cette étude a démontré la conformité pauvre avec les indications diabétiques actuelles. Il y a un besoin urgent de réexaminer comment les indications sont disséminées et sont exécutées dans les hôpitaux de secteur publics, africains et du sud si la preuve a basé des indications sont d'avoir n'importe quel impact sur soins aux patients.

\section{Introduction}

With over 285 million people with diabetes worldwide, there is no doubt that this disease is a major health problem throughout the world. Diabetes is the fourth leading cause of death in the Western world and the leading cause of chronic renal failure. ${ }^{1}$ Diabetes also significantly contributes to morbidity and mortality associated with ischaemic heart disease and cerebrovascular accidents. 
Diabetes is not only a disease of affluent countries - increased urbanisation, with a more westernised diet and sedentary lifestyle, has led to a large number of patients developing diabetes in developing countries. It is estimated that in 2010 there were 4 million people with diabetes in South Africa, equating to a prevalence of $4.5 \%$ of the general population.

\section{Key focus}

The benefits of good glycaemic control were demonstrated by two major studies: the Diabetic Control and Complication Trial and the United Kingdom Prospective Diabetes study performed in 2003. Both studies concluded that development of complications in diabetic patients was directly related to their glycaemic level. ${ }^{2,3}$ In a nine-year follow-up study involving 4662 men and 5570 women, Kay-Tee Khaw (2003, cited in Hereyan, 2004) $)^{4}$ demonstrated that a $1 \%$ rise in the level of glycated haemoglobin $\left(\mathrm{HbA}_{1 \mathrm{c}}\right)$ was associated with an increased risk of death of up to $28 \%$ and $24 \%$ in women and men respectively. $\mathrm{HbA}_{1 \mathrm{c}}$ levels below $5 \%$ were associated with lowest rates of cardiac complications and death. However, such levels were also associated with significant hypoglycaemia. ${ }^{5}$

In a 2004 study Klausen et al. ${ }^{6}$ showed that the presence of micro-albuminuria was a predictor of early renal pathology, and levels $>4.8 \mu \mathrm{g} / \mathrm{min}$ were strongly associated with coronary heart disease and death from cardiac events. Based on international research findings, the Society for Endocrine, Metabolism and Diabetes of South Africa (SEMDSA) developed guidelines for the management of diabetic patients in South Africa, which were updated in 2009. The guidelines set a target for $\mathrm{HbA}_{1 \mathrm{c}}$ of $<7 \%$ for all diabetic patients, as well as specific targets for lipids, blood pressure, body mass index and when various monitoring assessments should be conducted. Regular monitoring and appropriate response to abnormal results have been shown to reduce complications such as myocardial infarction, cerebrovascular accidents and retinopathy in diabetic patients. ${ }^{5}$

\section{Background}

Adherence to diabetic guidelines when managing diabetic patients has been shown not only to reduce complications but also to improve utilisation of resources. In 1995 a study was performed in South Africa amongst specialist physicians and general practitioners with an interest in diabetes management who had been trained in the American Diabetes Association Guidelines targets. In this study doctors received financial incentives to adhere to the guidelines. Improved diabetes management based on the guidelines resulted in a $90 \%$ reduction in hospitalisation amongst diabetic patients, demonstrating conclusively that with incentives and motivation adherence to guidelines was possible, and that such adherence to guidelines benefits patients. ${ }^{7}$ A number of studies have reported innovative ways to remind doctors to follow guidelines, including reminders by nurses, computer prompts and use of standardised recording sheets which show which investigation needs to be performed and when. Under research conditions all of these methods have been shown to be useful in improving adherence to guidelines. ${ }^{8,9}$

\section{Trends}

However, many studies have shown that doctors in general do not adhere to guidelines. A study carried out in Norway in 1997 which reviewed patient data retrospectively to evaluate adherence to National Diabetic Guidelines by general practitioners concluded that doctors were not adhering to the guidelines. Analysis by the Centers for Disease Control and Prevention found that $<5 \%$ of diabetic patients in the United States of America received care equivalent to what is specified in the American Diabetes Association guidelines. ${ }^{8,10}$

\section{Objectives}

The aim of this study was to assess doctors' compliance with the core process of care as stated in the SEMDSA diabetes guidelines, and also to review demographic and clinical profiles of diabetic patients at a regional hospital in KwaZulu-Natal.

\section{Contribution to the field}

The SEMDSA guidelines have been widely distributed in South Africa and are available for those running diabetic services throughout the country. To date there has not been an evaluation of adherence of doctors to the SEMDSA diabetic guidelines at Ngwelezane Hospital, and this study aims to address this gap.

\section{Ethical considerations}

Permission to conduct this study was obtained from the Research and Ethics Committee of the University of KwaZuluNatal (Ref. No. BE165/010), the provincial Department of Health and hospital management.

\section{Potential benefits and hazards}

This study highlights the need for improve adherence to guidelines amongst primary healthcare providers to help reduce complications of diabetes. There was no direct hazard since the study took the form of a data review without human participants. The data were only accessible to the researcher and remained locked in a safe place, where they will be for years.

\section{Trustworthiness}

\section{Reliability}

The data collection material was taken directly from the SEMDSA guidelines.

\section{Validity}

This was a descriptive study and hence may not be generalised outside of its context; also, this study was not able to consider all possible confounders.

\section{Methods}

\section{Materials}

The checklists in the patient records that were assessed in this study included the following: patient demographic data and $\mathrm{HbA1c}$, lipid profile, blood pressure, weight and/or body mass index, waist circumference, comprehensive foot examination, 
micro-albuminuria, serum creatinine, eye examination, referral to dietician and diabetic nurse educator. They also state how many times these processes of care were carried out, and their values.

\section{Setting}

The study was performed at a large regional hospital 180 $\mathrm{km}$ north of Durban between June and October 2011. The diabetic clinic sees 2600 patients per year and receives referrals from 16 clinics.

\section{Design}

A study sample of 750 records was chosen, representing 30\% of the 2600 patients with type 2 diabetes who are seen annually at the clinic. Inclusion criteria were regular attendance at the diabetic clinic for $>1$ year and type 2 diabetes. Patients with type 1 diabetes (defined as onset of diabetes prior to 40 years of age and presentation with ketonuria) and patients with gestational diabetes were excluded from the study.

\section{Procedure}

Records were assessed against the SEMDSA guidelines. A random number between one and three was chosen and then every third record was chosen until 750 charts had been selected. ${ }^{11}$

\section{Analysing}

Data were captured onto an Excel spreadsheet and analysed using the Statistical Package for Social Sciences. Descriptive analysis such as mean, median, mode and interquartile range were use to summarise the data, and results were presented in tables and graphs.

\section{Results}

Of the 750 files reviewed, 514 were on females (68.5\%) and 236 on males (31.5\%). The mean age was 53 years (40-90 years), $82 \%$ were unemployed, $95.6 \%$ (717 out of 750$)$ were Black people, $2.7 \%$ (20 out of 750 ) were White people and $1.7 \%$ (13 out of 750) were Indian people. The average number of visits to the diabetic clinic was 5 per year (2 to 10 visits).

Only $24 \%$ (180 out of 750 ) of the patients had their $\mathrm{HbA}_{1 \mathrm{c}}$ checked in the preceding year (Table 1 [a-b]). Of the 180 who had their $\mathrm{HbA}_{1 \mathrm{c}}$ checked, only $16.7 \%$ (30 out of 180) had values within target $(<7 \%)$. Twenty two patients had the $\mathrm{HbA}_{1 \mathrm{c}}$ check repeated, of whom only two had normal values. Only two patients had their $\mathrm{HbA}_{1 \mathrm{c}}$ checked on more than two occasions, and both had values higher than the target.

Five hundred and fifty six (74\%) patients had total cholesterol checked at least once. The mean value was $4.9 \mathrm{mmol} / \mathrm{L}$ ( $2 \mathrm{mmol} / \mathrm{L}-9 \mathrm{mmol} / \mathrm{L})$ (Table 2 [a-c]). Of those who had their cholesterol measured, $44.2 \%$ (246 out of 556 ) had normal values of total cholesterol. No patient had their low-density lipoprotein (LDL) or high-density lipoprotein (HDL) measured. Triglycerides were recorded as assessed in 295 (39.3\%) of patients, of whom $43.1 \%$ (127 out of 295 ) had values within the target of $<1.7 \mathrm{mmol} / \mathrm{L}$.
TABLE 1a: Frequency of $\mathrm{HbA}_{1 c}$ when assessed for the first time and at quarterly visits.

\begin{tabular}{lcc}
\hline Valid & $\boldsymbol{f}$ & $\mathbf{\%}$ \\
\hline Performed & 180 & 24 \\
Not performed & 570 & 76 \\
\hline Total & $\mathbf{7 5 0}$ & $\mathbf{1 0 0}$ \\
\hline
\end{tabular}

$f$, frequency.

TABLE 1b: $\mathrm{HbA}_{1 c}$ analysis at quarterly clinic visits.

\begin{tabular}{lccccc}
\hline Valid & $\boldsymbol{n}$ & Minimum (\%) & Maximum (\%) & Mean (\%) & sd \\
\hline $\mathrm{HbA}_{1 \mathrm{c}}{ }^{2}$ & 180 & 5.4 & 15.4 & 9.7 & 2.4206 \\
$\mathrm{HbA}_{1 \mathrm{c}} 2$ & 22 & 6.4 & 12 & 8.9 & 1.6886 \\
$\mathrm{HbA}_{1 \mathrm{c}} 3$ & 2 & 8 & 8.4 & 8.2 & 0.2828 \\
\hline
\end{tabular}

sd, Standard deviation; \%, percentage; $n$, number of patients with $\mathrm{HbA}_{1 \mathrm{c}}$ performed; $\mathrm{HbA}_{1 \mathrm{c}}$ $1,2,3$, quarterly values.

TABLE 2a: Lipid profile frequency.

\begin{tabular}{lcccc}
\hline Valid & $\boldsymbol{f}$ & $\mathbf{\%}$ & Valid (\%) & Cumulative (\%) \\
\hline Performed & 556 & 74.1 & 74.1 & 74.1 \\
Not performed & 194 & 25.9 & 25.9 & 100 \\
\hline Total & $\mathbf{7 5 0}$ & $\mathbf{1 0 0}$ & $\mathbf{1 0 0}$ & - \\
\hline
\end{tabular}

$f$, frequency; \%, percentage.

TABLE 2b: Quarterly lipid profile and analysis.

\begin{tabular}{lcccc}
\hline Valid & $\boldsymbol{f}$ & $\mathbf{\%}$ & Valid (\%) & Cumulative (\%) \\
\hline 1 & 344 & 45.9 & 61.9 & 61.9 \\
2 & 170 & 22.7 & 30.6 & 92.4 \\
3 & 42 & 5.6 & 7.6 & 100 \\
\hline Total & $\mathbf{5 5 6}$ & $\mathbf{7 4 . 1}$ & $\mathbf{1 0 0}$ & - \\
\hline
\end{tabular}

$f$, frequency.

TABLE 2c: Quarterly lipid profile and analysis.

\begin{tabular}{lcc}
\hline Valid & $\boldsymbol{f}$ & $\mathbf{\%}$ \\
\hline Not performed & 194 & 25.9 \\
& 750 & 100 \\
\hline
\end{tabular}

$f$, frequency.

TABLE 3a: Blood pressure values at six visits to diabetic clinic.

\begin{tabular}{lcccccc}
\hline $\boldsymbol{n}$ & SBP 1 & DBP 1 & SBP 2 & DBP 2 & SBP 3 & DBP 3 \\
\hline Valid & 750 & 750 & 750 & 750 & 750 & 750 \\
Not Performed & 0 & 0 & 0 & 0 & 0 & 0 \\
Median & 136 & 84 & 137 & 83 & 136 & 82 \\
Mode & 114 & 70 & $132 \dagger$ & 70 & 130 & 84 \\
Minimum & 90 & 43 & 87 & 42 & 87 & 49 \\
Maximum & 246 & 133 & 234 & 140 & 228 & 180 \\
\hline
\end{tabular}

SBP, systolic blood pressure; DBP, diastolic blood pressure.

Multiple modes exist; the lowest value is shown.

$\dagger$, Multiple modes exist. The smallest value is shown.

$n$, number of patients with Blood pressure performed.

TABLE 3b: Blood pressure values at six visits to diabetic clinic.

\begin{tabular}{lcccccc}
\hline $\boldsymbol{n}$ & SBP 4 & DBP 4 & SBP 5 & DBP 5 & SBP 6 & DBP 6 \\
\hline Valid & 749 & 749 & 718 & 718 & 688 & 687 \\
Not performed & 1 & 1 & 32 & 32 & 62 & 63 \\
Median & 136 & 82 & 141 & 82 & 140 & 82 \\
Mode & 132 & 70 & $120 \dagger$ & 70 & 142 & $70 \dagger$ \\
Minimum & 60 & 45 & 60 & 42 & 68 & 48 \\
Maximum & 215 & 182 & 255 & 181 & 1161 & 147 \\
\hline
\end{tabular}

Multiple modes exist; the lowest value is shown.

SBP, systolic blood pressure; DBP, diastolic blood pressure.

$\mathrm{SBP}$, systolic blood pressure; DBP, diastolic blood press
$\dagger$, Multiple modes exist. The smallest value is shown.

$n$, number of patients with Blood pressure performed.

All patients had their blood pressure measured on at least three occasions during the year (Table $3[a-b]$ ), and the vast majority of patients had their blood pressure checked on each visit. Of the 750 patients only 39.6\% (297 out of 750 ) had a systolic blood pressure at or below the target of $130 \mathrm{mmHg}$, and only $38.7 \%$ (290 out of 750 ) a diastolic blood pressure at 
or below the target of $80 \mathrm{mmHg}$. Seven hundred and thirty three patients had their weight recorded at least once, and the mean weight was $86 \mathrm{~kg}(45 \mathrm{~kg}-153 \mathrm{~kg})$. Ninety nine per cent of patients did not have any record of body mass index, and waist circumference was not recorded in $97.6 \%$ (732 out of 750) of files. Only 6.1\% (46 out of 750) of files had documented evidence of foot examination having been performed, and of the 46 patients who did have their feet examined, nine had abnormal findings.

Urine dipstick testing was performed in all patients, of whom $24.4 \%$ (183 out of 750) had persistent proteinuria. Of the 567 patients without proteinuria (Figure 1), only 3.9\% (22 out of 567) had their urine tested for micro-albuminuria, and five of these had abnormal results.

Eighty-seven per cent of patients had their blood tested for serum creatinine. The hospital has a functional ophthalmology department, and $43 \%$ of the patients (323 out of 750 ) had at least one eye examination in the preceding year. Of the 323 patients who had an eye examination, cataracts were diagnosed in 15 patients, diabetic retinopathy in 62 patients, and two patients were blind.

The SEMDSA guidelines recommend referral of diabetic patients to a nurse educator to reinforce diabetic education, and to a dietitian to help patients make appropriate modifications to their eating habits. However, there was a poor record of referral to the nurse educator and only 120 patients were referred to the dietitian.

\section{Discussion}

The results of this study are disappointing, considering that the SEMDSA guidelines have been widely distributed and are freely available, and that this study was performed at a diabetic clinic in a regional hospital. The results show poor compliance with processes of care (when to do which investigations), and poor patient outcomes as shown by the large numbers with elevated $\mathrm{HbA}_{1 \mathrm{c}}$ levels, abnormal lipid results, poorly controlled blood pressure, proteinuria and eye abnormalities.

In terms of outcome-related results, these finding are similar to the baseline finding of a study performed at the Pretoria Academic Hospital in 2004: ${ }^{9}$ a baseline mean $\mathrm{HbA}_{1 \mathrm{c}}$ of 9.77 in the Pretoria study compared to 9.708 in our study. However, our study differs from the Pretoria study in that only $6 \%$ of patients had a foot examination in this study, compared to $23.4 \%$ of patients in Pretoria prior to the intervention, but is similar to the $4.7 \%$ found in a Cape Town study. ${ }^{9,12}$

In terms of process-related results, the total cholesterol was measured in $74.1 \%$ of patients, which compares very favourably with the baseline results in the Pretoria study, which found that only $20.6 \%$ of patients had their cholesterol checked prior to their intervention. HDL and LDL were not assessed for any of the 750 patients in our study, despite the

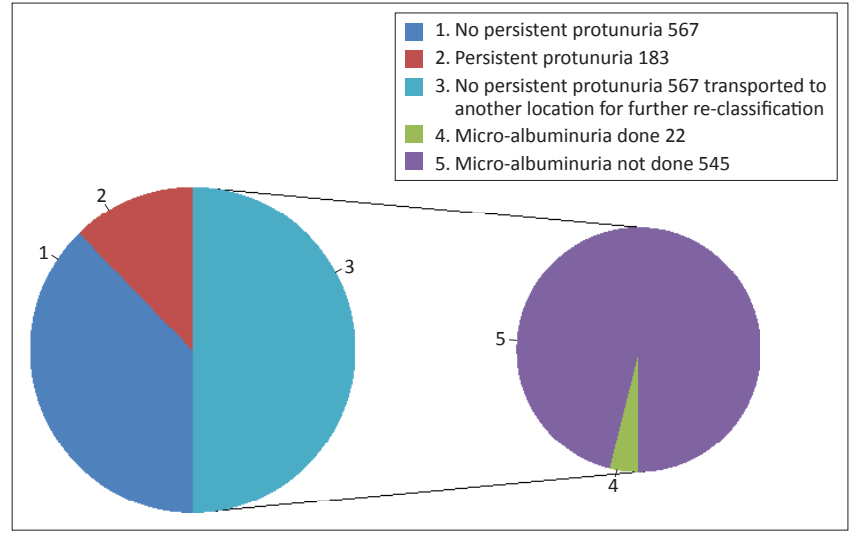

FIGURE 1: Presence of persistent proteinura and micro-albuminuria.

guideline recommending that HDL, LDL, total cholesterol and triglycerides be measured at least twice a year. Other studies have only reported lipid profile, which is often not checked at the prescribed intervals., ${ }^{9,12}$

This study has confirmed what other studies have shown - that processes of care are performed well when they are part of routine care and part of someone's day-today responsibility. ${ }^{7}$ Blood pressure and urine dipstick assessments carried out by nursing staff were well recorded in the notes. However, patients with no proteinuria, who needed to have their urine assessed for micro-albuminuria, were not well assessed. A standing order for nursing staff to test urine for micro-albuminuria if the urine is negative for protein may be a way to improve compliance in this area.

There has been much discussion recently in South Africa about the need to re-engineer primary health care. A key component of the re-engineering document to ensure adequate human resources for the provision of health care is task shifting, where routine tasks are delegated to the lowest level of competency. ${ }^{13}$ The development of midlevel workers, currently being trained at the Universities of Pretoria, Witwatersrand and Walter Sisulu, could provide the opportunity to delegate many of these processes of care to competent healthcare.

However, abnormal results need to be acted upon if patient care is to improve, and simply task shifting the responsibility to ensure that tests are performed and blood pressures are checked will not improve patient outcomes. Acting on abnormal results must be the responsibility of the doctor caring for the patient. The finding that $60 \%$ of patients had abnormal blood pressure readings suggests that doctors are either not recognising abnormal results or are not responding appropriately to abnormal results - both of which potentially lead to poor outcomes and development of complications in patients. ${ }^{2,3}$

The findings of this study concur with a number of other South African and international studies which have shown that overall management of diabetic patients, knowledge of patients about their illness and management of the diabetic foot are suboptimal. ${ }^{12,14}$ A study in Norway amongst primary 
healthcare providers found a low level of adherence to diabetic guidelines, despite substantial investment in circulating guidelines and educating doctors on them. ${ }^{10}$

Recommendations from the study in Pretoria ${ }^{9}$ which showed improvement in processes and outcome of care for diabetic patients include use of a structured consultation schedule and a programme of continuing medical education for those involved in care of diabetic patients. There is, however, no evidence that benefits gained during the study period were sustained once the study was finished. Other studies have recommended organisational support and computertracking systems to help doctor implement guidelines. ${ }^{8}$

South Africa is known for a progressive Constitution, great legislation and well thought out policies; however, poor implementation of many of these has impacted negatively on service delivery to those who need it most. ${ }^{15}$ There is a danger that the healthcare profession will end up in the same trap - great evidence-based guidelines, unless consistently implemented, will have no impact on improving the quality of care provided to patients.

\section{Limitations of the study}

The major limitation to this study was time constraints, which limited the number of records that we could assess.

\section{Conclusions and recommendations}

This study has highlighted poor processes of care and poor patient outcomes at a regional hospital with a dedicated diabetic referral clinic. It highlights the need to review how guidelines are distributed and implemented if patient management and outcomes are to be improved. Recommendations from this study include the following:

- The need to assess knowledge of common guidelines as an exit competency when students leave medical school.

- The need to teach and assess ability of healthcare professionals to update their knowledge of common guidelines.

- Development of a culture of excellence where reviews, audits and quality improvement projects are part of the standard operating system within all units.

- Institutionalising quality improvement initiatives, where regular audit of the processes and outcomes of care by those involved in patient care are monitored.

- Conducting regular continuing medical education sessions which focus on evidence-based management of diabetic patients.

- Carrying out more research on innovative ways to ensure that guidelines are implemented.

\section{Acknowledgements}

We thank Sam Ross for helping to review the draft manuscript and U.P. Ariguzo for support during the whole study.

\section{Competing interests}

The authors declare that they have no financial or personal relationship(s) which may have inappropriately influenced them in writing this paper.

\section{Authors' contributions}

O.J.I. (University of KwaZulu-Natal) was project leader and responsible for project design, data collection and presentation of the results. A.R. (University of KwaZuluNatal) made major corrections during the writing of the manuscript, and O.C.H. (University of KwaZulu-Natal/ Ngwelezane Hospital) also corrected the manuscript.

\section{References}

1. Epidemiology and Morbidity, diabetes and impaired glucose tolerance: Global Burden: prevalence and projections, 2010 and 2030 . International Diabetes Federation Diabetes Atlas [homepage on the Internet] 2010 [cited 25 Feb. 2010]. Available from: http://www.diabetesatlas.org

2. Genuth S, Eastman R, Kahn R, et al. Implication of the United Kingdom Prospective diabetes study, Diabetes Care. 2003; 26 (suppl. 1).

3. The Diabetes Control and Complications Trial and Follow-up study. National Diabetes Information Clearing house (NDIC) [homepage on the Internet] May 2008 [cited 23 Feb. 2010]. Available from: http://diabetes.niddk.nih.gov/dm/pubs/ control/index.htm

4. Hereyan A. High blood sugar increases death risk for non diabetics too. [homepage on the Internet] October 2004 [cited 13 Mar. 2010]. Available from http://www. emaxhealth.com/23/709.htm

5. Society for Endocrinology, Metabolism and Diabetes of South Africa: Guidelines for Diagnosis and Management of Type 2 Diabetes Mellitus for Primary Health for Diagnosis and Management of Type 2 Diabetes Mellitus for Primary Health http://www.semdsa.org.za

6. Klausen K, Borch-Johnsen K, Feldt-Rasmussen B, et al. Very low levels of Microalbuminuria are Associated with increased risk of coronary heart disease and death Independently of renal function, hypertension and diabetes [homepage on the internet] Circulation, March 2004 [cited 25 Feb. 2010]. Available from: on the internet] Circulation, March 2004 [cited 25 Fir.//irc.ahajournals.org/cgi/content/full/110/1/32

7. Distiller L. Improved diabetes management in South Africa: the case for a Capitation model. Diabetes Voice. 2004;49: p.16-18.

8. Sue Kirkman M, Williams S, Caffrey $\mathrm{H}$, et al. Impact of a program to improve adherence to diabetes guidelines by primary care physicians. Diabetes Care. 2002;25(11):19461951. http://dx.doi.org/10.2337/diacare.25.11.1946, PMid:12401737

9. Van Zyl D, Rheeder P. Physician education programme improves quality of diabetes care. JEMDSA. 2005;10(3):86-90.

10. Hetlevik I, Holmen J, Midthjell K. Treatment of diabetes mellitus- physicians' Adherence to clinical guideline in Norway. Scand J Prim Health Care. 1997;15:193197. http://dx.doi.org/10.3109/02813439709035027, PMid:9444723

11. Joubert G, Ehrlich R. Population and sampling. Epidemiology: A research manual for South Africa. 2nd ed. Cape Town: Oxford University Press; 2007; 94-97.

12. Levitt NS, Zwarenstein MF, Doepfmer S, Bawa AA, Katznellenbogen J, Bradshaw D. Public sector primary care of diabetics - a record of quality of care in Cape Town. S Afr Med J. 1996;86(suppl. 8):1013-1017. PMid:9180772

13. Re-engineering primary health care for South Africa; human resource implications. Presentation HWSETA [homepage on the Internet] September 2011 [cited 10 Mar. 2012]. Available from: http://www.hwseta.org.za

14. Matwa P, Chabeli MM, Muller M, Levitt N. Experiences and guidelines for foot care practices of patients with diabetes mellitus. Curationis 2003;26(1)11-21.

15. Chikulo BC. Development Policy in South Africa: A Review. DPMN Bulletin. 2003;10(2) [cited 10 Mar. 2012]. Available from: www.dpmf.org/images/south-Africa-devtpolicy-chikulo.html 